\title{
Effects of bronchial blockers on gas exchange in infants with one- lung ventilation: a single-institutional experience of 22 cases
}

\author{
Li Zhang, Yu-Ping Wang, Xiao-Fen Chen, Zi-Rogn Yan, Min Zhou^^ \\ Department of Anesthesiology, Fujian Maternity and Child Health Hospital, Affiliated Hospital of Fujian Medical University, Fuzhou, China \\ Contributions: (I) Conception and design: L Zhang, M Zhou; (II) Administrative support: M Zhou; (III) Provision of study materials or patients: L \\ Zhang, YP Wang, XF Chen, ZR Yan; (IV) Collection and assembly of data: L Zhang, YP Wang; (V) Data analysis and interpretation: L Zhang, YP \\ Wang; (VI) Manuscript writing: All authors; (VII) Final approval of manuscript: All authors. \\ Correspondence to: Min Zhou. Department of Anesthesiology, Fujian Maternity and Child Health Hospital, Affiliated Hospital of Fujian Medical \\ University, Fuzhou, China. Email: zm405@163.com.
}

\begin{abstract}
Background: One-lung ventilation (OLV) in infants is a commonly used airway technique during thoracic surgery. Current research has primarily focused on the operation of the airways and the occurrence of complications. However, there has been minimal data on the pulmonary gas exchange in infants before and after OLV. This study aimed to assess the efficacy of bronchial blockers (BBs) on the pulmonary gas exchange in infants with OLV.

Methods: A total of 22 infants requiring OLV from January 2017 to August 2019 were included in this study. OLV was achieved by placing BBs outside the endotracheal tube, and all surgeries were performed by the same experienced anesthesiologist. Numerous clinical features, including the oxygenation index (OI), alveolar-arterial oxygen tension gradient $\left(\mathrm{P}_{\mathrm{A}-\mathrm{a}} \mathrm{O}_{2}\right)$, pulmonary dynamic compliance (Cdyn), OLV time, pulmonary collapse time, degree of pulmonary collapse at the operative side, operative time, and immediate hemodynamic indexes before and after intubation were assessed. Data from the arterial blood gases and the ventilator's parameters were obtained at three time points: 15 minutes before OLV (pre-OLV), 15 minutes after the initiation of OLV (during OLV), and 15 minutes after the termination of OLV (post-OLV).

Results: For all patients, the pulmonary gas exchange during OLV was significantly different from both pre-OLV and post-OLV. However, no significant changes of pulmonary function were observed before and after OLV. Extended OLV time was associated with decreased OI and Cdyn, and increased $\mathrm{P}_{\mathrm{A}-\mathrm{a}} \mathrm{O}_{2}$ gradient $(\mathrm{P}<0.001)$. In addition, no significant changes of hemodynamic indexes before and after intubation were detected. The degree of lung collapse on the operational side during OLV was optimal.

Conclusions: In this study, the efficacy of BBs on the pulmonary gas exchange in infants with OLV was assessed. The results suggested that although each parameter of pulmonary function pre-OLV were similar to those of post-OLV, an extended period of OLV may lead to compromised lung function.
\end{abstract}

Keywords: One-lung ventilation (OLV); bronchial blockers (BBs); infants; pulmonary function; anesthesia

Submitted Oct 29, 2020. Accepted for publication Dec 13, 2020.

doi: $10.21037 /$ tp-20-391

View this article at: http://dx.doi.org/10.21037/tp-20-391

\section{Introduction}

Video-assisted thoracoscopic surgery (VATS) is a typical approach that is increasingly utilized in thoracic surgery.
The key to the success of VATS is the maximization of intrathoracic visibility by optimizing the quality of the pulmonary isolation and deflation in a closed thoracic cavity. VATS typically includes lung deflation on the

\footnotetext{
^ ORCID: 0000-0003-2800-4196.
} 
surgical side, and one-lung ventilation (OLV) on the nonsurgical side (1-4).

Previous studies $(3,5,6)$ have revealed that OLV offers separate ventilation mechanisms for both lungs by blocking one end of the tracheal catheter. This helps to prevent nonoperational side pulmonary infections and helps to prevent operative side pulmonary hemorrhage from contaminating the healthy areas, and provides a better field of vision for the surgery. At present, OLV is used to allow for optimum surgical exposure in patent ductus arteriosus, aortic coarctation repair, pleurodesis and decortication, pulmonary biopsy, mediastinal biopsy, congenital pulmonary airway malformation, pulmonary sequestration, congenital cystic adenomatoid malformation, and much more (3,7-10).

Endobronchial intubation with a double-lumen bronchial tube, also known as double-lumen endotracheal tube (DLT), is the most common method of anesthesia in OLV. Alternatively, a normal one-lumen tube (OLT) may be inserted into the healthy side of the main bronchus to maintain OLV. Another alternative technique for achieving OLV involves the use of a device called a bronchial blocker (BB). Compared to the DLT and the OLT, the external $\mathrm{BB}$ of the endotracheal tube is not limited by the type of endotracheal tube, and it does not sliding up and down the airway, thus ensuring the effective isolation of the lung. Therefore, it has been widely used in infants and children $(3,5,11,12)$.

To date, the majority of studies have focused on the related operation of the airway and the occurrence of postoperative complications (13-15), while there is a scarcity of data on pulmonary physiological changes in infants before and after the exchange of lung gases during OLV. Therefore, the purpose of this study was to investigate the effects of OLV combined with BBs on infant pulmonary physiology before and after the exchange of lung gases during VATS.

We present the following article in accordance with the MDAR checklist (available at http://dx.doi.org/10.21037/ tp-20-391).

\section{Methods}

This study was approved by the Ethics Committee of the Fujian Maternity and Child Health Hospital (Ethics No: 268, December 12, 2016). Written informed consent was signed by the guardians of all patients. The study was conducted in accordance with the Declaration of Helsinki (as revised in 2013). A total of 22 patients undergoing elective thoracic surgery from January 2017 to August 2019 were eligible for this study. The American society of anesthesiologists (ASA) was classified as Grade I-III,The patients ranged from 2-12 months of age and weighed between $3.5-10 \mathrm{~kg}$. Patients whose family members did not consent to participate in the study, and patients who were complicated with heart and brain dysfunctions were excluded from the study. The exit criteria were as follows: the fiberoptic bronchoscope could not be inserted into the endotracheal tube; oxygen saturation could not be maintained during surgery thereby requiring conversion to double-lung ventilation; unanticipated surgical difficulty requiring conversion to thoracotomy; and unanticipated difficulty in the airways. There were 11 cases of diaphragmatic hernia, 5 cases of pulmonary cystadenoma, 8 cases of lung/mediastinal mass, and 5 cases of pulmonary bullae. During surgery, 5 cases were converted to thoracotomy and 2 cases were converted to double ventilation of the lungs. The male to female ratio was 13:9, and the ratio of left lung to right lung was 15:7.

\section{Anestbetic procedures}

All patients received VATS. Patients were sedated with $0.1 \mathrm{mg} / \mathrm{kg}$ midazolam and a multi-function monitor was used to monitor arterial blood pressure (BP), heart rate (HR), pulse oxygen saturation $\left(\mathrm{SpO}_{2}\right)$, and electrocardiograph (ECG). After all monitoring indices were stable, anesthesia was induced by intravenous injection of propofol at 2-3 $\mathrm{mg} / \mathrm{kg}$ (production batch: 19214050, B. Braun Melsungen AG, Germany), fentanyl at $3-5 \mu \mathrm{g} / \mathrm{kg}$ (production batch: 91D06111, Yichang Humanwell Pharmaceutical Co., Ltd., China), and rocuronium at $0.6 \mathrm{mg} / \mathrm{kg}$ (H20140847 Registration No. N.V. OrganonM Hameln Pharmaceuticals GmbH, Germany).

After induction of anesthesia, the smallest $5 \mathrm{~F} \mathrm{BB}$ (Hangzhou Tampa Medical Technology Co., Ltd.) was first inserted into the patient's trachea $2 \mathrm{~cm}$ from the vocal cords, and a cuffed endotracheal tube (ETT) was inserted via the cords adjacent to the extraluminal blocker. A $2.2 \mathrm{~mm}$ fiberoptic bronchoscope (PENTAX F1-9RBS Japan) was then placed via the ETT to visualize and control the entry of the blocker into the left or right mainstem bronchus. Under direct vision, the blocking balloon was slowly inflated while the tracheal tube continued to ventilate the right or left lung. Subsequently, invasive radial artery puncture was performed to accurately monitor systolic arterial blood pressure (SBP), diastolic blood pressure (DBP), mean 
arterial pressure (MAP), and blood gas readings. End-tidal carbon dioxide $\left(\mathrm{CO}_{2}\right)$ was also measured with a regular Life Scope monitor (BSM-3562 Nihon Kohden Japan).

Manual breathing and auscultations were performed to determine the respiratory sounds of both lungs. When respiratory sounds disappeared on the surgical side, fiberoptic bronchoscopy was used to evaluate the location of the BBs, the length of placement, and the depth of the endotracheal intubation. After the balloon was deflated, it was then connected to a machine (Primus, Dräger Medical Equipment Co., Ltd. Germany) for double-lung pressure control ventilation with fraction of inspired oxygen $\left(\mathrm{FiO}_{2}\right)$ at $50 \%$, positive end expiratory pressure (PEEP) of $3-5 \mathrm{mmHg}(1 \mathrm{mmHg}=0.133 \mathrm{kPa})$, inspiratory/expiratory ratio (I:E) of $1: 1$, tidal volume (VT) of $8-10 \mathrm{~mL} / \mathrm{kg}$, respiratory frequency (R) of 20-25 times per minute, and oxygen flow rate of $2-3 \mathrm{~L} / \mathrm{min}$. Patients were placed in VATS position, the position of the catheter was determined again by fiberoptic bronchoscope prior to the operation. After entering the chest cavity of the affected side, the balloon was filled with the same volume of bronchial occlusion gas and OLV was initiated using volume-controlled ventilation $\left(\mathrm{FiO}_{2} 40-80 \%\right.$, PEEP 3-5 mmHg, I:E=1:1, VT 4-6 mL/kg, R 25-30 times/min, and oxygen flow rate $2-3 \mathrm{~L} / \mathrm{min}$ ). Arterial oxygen saturation was maintained between $92 \%$ and $96 \%$. Remifentanil at $0.2-0.5 \mu \mathrm{g} \cdot \mathrm{kg}^{-1} \cdot \mathrm{min}^{-1}$ (production batch: 90A10141, Yichang Humanwell Pharmaceutical Co., Ltd., China) and 1-3\% sevoflurane (production batch: S235M817, Baxter Healthcare Corporation) were used for the maintainance of anesthesia.

Notably, if $90 \%$ desaturation occurred during the operation, the lung isolation operation was terminated and normal two-lung ventilation was temporarily resumed. In addition, BF fluctuations of the infants were maintained at $\pm 20 \%$ of the basal $\mathrm{BF}$, heart rate between 120-160 beats/min, and end-tidal $\mathrm{CO}_{2}$ of $35-45 \mathrm{mmHg}$. Rocuronium $(0.1 \mathrm{mg} / \mathrm{kg})$ was administered when necessary. At the conclusion of the operation, patients were repositioned from the lateral to the supine position, and bilateral lung ventilation was restored. Pulmonary re-expansion ventilation, where the collapsed lung was immediately dilated at a pressure of $30 \mathrm{~cm}$ water $\left(\mathrm{H}_{2} \mathrm{O}\right)$ for 15 to 20 seconds, was adopted during the operation at the following times: after endotracheal intubation, after the onset of OLV (ventilation every 30 minutes), and after the end of OLV. All operations were carried out by the same experienced anesthesiologist.

\section{Physiological indicators}

The primary indicators including the oxygenation index $\left(\mathrm{OI}=\mathrm{P}_{\mathrm{a}} \mathrm{O}_{2} / \mathrm{FiO}_{2}\right.$, where $\mathrm{P}_{\mathrm{a}} \mathrm{O}_{2}$ is the arterial oxygen pressure), the alveolar-arterial oxygen tension gradient $\left(\mathrm{P}_{\mathrm{A}-\mathrm{a}} \mathrm{O}_{2}\right)$, and pulmonary dynamic compliance $(\mathrm{Cdyn}=$ VT/ - Peak PEEP) were detected by blood gas analysis (GEM Premier 4000, Instrumentation Laboratory Company, America) on collected arterial blood at three time points: 15 minutes before OLV (pre-OLV), 15 minutes after the beginning of OLV (during OLV), and 15 minutes after the end of OLV (post-OLV). The secondary outcomes included OLV duration, the effects of OLV duration on pulmonary physiology, the time of pulmonary collapse (OLV to grade II), operation time, hemodynamic indicies (MAP and HR) before and after intubation, and the degree of pulmonary collapse (grade I: complete collapse of the diseased lung; grade II: there is a small amount of residual gas in the diseased lung, but it does not affect the lung collapse; grade III: partial collapse of the diseased lung requiring further intervention, but does not affect the operation (16).

\section{Statistical analysis}

Statistical analysis was performed using SPSS software (26.0 Version, IBM Corp, Armonk, NY, USA). Normally distributed output data was presented as a mean \pm SD and compared via $t$-test. Skewed data were summarized as the median (interquartile range). A comparison of pulmonary gas exchange indicies pre-OLV, during OLV, and postOLV was performed using repeated measurement analysis of variance. Univariable linear regression was conducted to analyze the relationship between predictor variables at each OLV time point and each of the three outcome variables. Categorical variables were shown as frequency (percentage) and were evaluated with $\chi^{2}$ test. Statistical significance was assumed when $\mathrm{P}$ value $<0.05$.

\section{Results}

\section{Pulmonary function indices of the infants}

There were significant differences in the pulmonary gas exchange during OLV compared to both pre-OLV and post-OLV. As shown in Figure 1A,B, the OI and Cdyn of all patients decreased from $411.18 \pm 35.34$ and $23.32 \pm 1.62$. pre-OLV to $235.10(70.57)$ and 14.41 (1.56) during OLV, respectively $(\mathrm{P}<0.001,95 \% \mathrm{CI}$ : 134.48 to 220.68 for OI; 

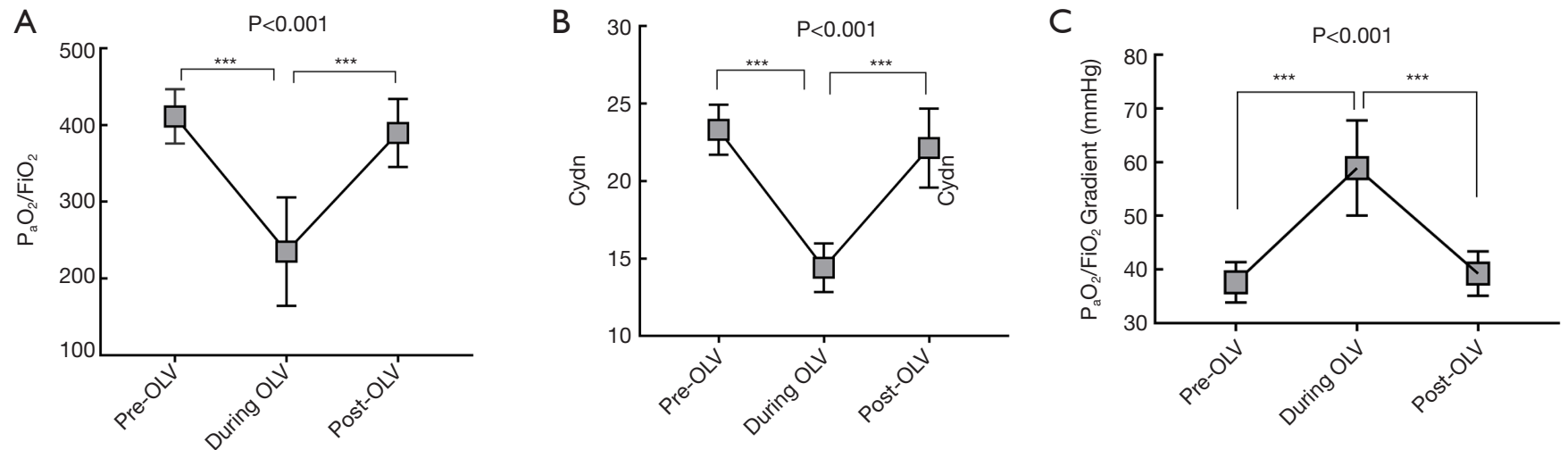

Figure 1 Pulmonary function of the infants (A) OI as measured by $\mathrm{P}_{\mathrm{a}} \mathrm{O}_{2} / \mathrm{FiO}_{2},(\mathrm{~B})$ Cdyn, and (C) $\mathrm{P}_{\mathrm{A}-\mathrm{a}} \mathrm{O}_{2}$ gradient for all infants were assessed at the three collected time points: 15 minutes before OLV (pre-OLV), 15 minutes after the beginning of OLV (during OLV), and 15 minutes after the end of OLV (post-OLV). ${ }^{* * *} \mathrm{P}<0.001$ vs. during OLV. OI, oxygen index; $\mathrm{P}_{\mathrm{A}-\mathrm{a}} \mathrm{O}_{2}$, alveolar-arterial oxygen tension; $\mathrm{P}_{\mathrm{a}} \mathrm{O}_{2}$, arterial oxygen pressure; $\mathrm{FiO}_{2}$, fraction of inspired oxygen; Cdyn, pulmonary dynamic compliance; OLV, one-lung ventilation.

$\mathrm{P}<0.001,95 \%$ CI: 7.64 to 10.18 for Cdyn). In addition, the $\mathrm{P}_{\mathrm{A}-\mathrm{a}} \mathrm{O}_{2}$ gradient pre-OLV was $56.5 \%$ lower than that during OLV [37.64 (3.76) vs. 58.89 (8.83); $\mathrm{P}<0.001$, 95\% CI: 25.88 to 16.62 ] (Figure $1 C$ ). The $\mathrm{OI}, \mathrm{P}_{\mathrm{A}-\mathrm{a}} \mathrm{O}_{2}$ gradient, and Cdyn were similar to those of pre-OLV after double-lung ventilation and appropriate pulmonary retraction following surgery, indicating no significant difference between preOLV and post-OLV.

\section{Intraoperative condition of the infants}

As shown in Table 1, the average duration of OLV, pulmonary collapse time, and operation time were 55.77 (6.81) minutes, 39.82 (5.72) minutes, and 71.14 (5.43) minutes, respectively. Prolonged OLV was associated with decreased OI and pulmonary compliance, and elevated $\mathrm{P}_{\mathrm{A}-\mathrm{a}} \mathrm{O}_{2}$ gradient. After the initial separation, lung insulation was graded good to excellent by the surgeon in 18 cases, and further manipulation of the blocker was required in 4 patients. Following the surgery, the 22 infants with endotracheal catheter were transferred to the intensive care unit for mechanical ventilation treatment, and no complications such as hypoxia and pulmonary respiratory insufficiency occurred. All subjects were successfully healed and discharged from the hospital.

\section{Hemodynamic analysis of the infants}

There were no statistically obvious differences in MAP and HR before and after intubation [60.32 (4.17) vs. 61.91 (2.69),
$\mathrm{P}=0.144$ for MAP; 118.73 (5.98) vs. 121.64 (4.92), $\mathrm{P}=0.125$ for HR; Table 2].

\section{Discussion}

Compared to traditional thoracotomy, VATS has the advantages of a smaller incision, less bleeding, a wider field of vision, and rapid postoperative recovery, making it the preferred method in older children $(11,17)$. In recent years, the improvement of the fiberoptic bronchoscope and the widespread application of BBs have rapidly increased the use of OLV in infants. However, the unique respiratory physiological characteristics of infants, such as weak respiratory support, abundant blood vessels, alveolar hypoplasia, low secretion by alveolar type II cells, high pulmonary stress, poor compliance, and a large physiological dead zone, can easily lead to ventilation or blood flow imbalance. The resultant changes in the respiratory physiological indexes can thus pose a challenge to achieving successful OLV $(18,19)$. Currently, research on OLV in infants largely focuses on the use of airway equipments and potential complications while undergoing thoracotomy. However, there have been limited studies examining the effects of OLV combined with BBs on lung function in infants. A previous report investigated the feasibility of OLV with BBs and single-cavity tubes in pediatric patients by monitoring the values of the arterial blood gases. The results demonstrated that the pediatric patients presented with acidosis, hypoxemia, low OI, and high capnia during thoractomy, but no comparisons of each 
features of low-volume and high-pressure. The overinflation of blocker balloons can cause airway damage (24), or herniate into the carina resulting in blockage of both bronchi.

This study was limited by the lack of distinction between the duration of pulmonary collapse and the age of the infants. As previous studies (25) have noted a close association between the duration of pulmonary collapse and the age groups of the patients, this should be further investigated.

\section{Conclusions}

Our study documented the major changes in lung function in infants undergoing OLV. Although each parameter of pulmonary function in pre-OLV were similar to the postOLV, an extended period of OLV may lead to compromised lung function. With the proper respiratory management during surgery, the lung can quickly recover to preoperative levels after double-lung ventilation, and therefore thoracoscopic surgery with OLV in infants is safe and feasible.

\section{Acknowledgments}

Funding: None.

\section{Footnote}

Reporting Checklist: The authors have completed the MDAR checklist. Available at http://dx.doi.org/10.21037/tp-20-391

Data Sharing Statement: Available at http://dx.doi. org/10.21037/tp-20-391

Conflicts of Interest: All authors have completed the ICMJE uniform disclosure form (available at http://dx.doi. org/10.21037/tp-20-391). The authors have no conflicts of interest to declare.

Ethical Statement: The authors are accountable for all aspects of the work in ensuring that questions related to the accuracy or integrity of any part of the work are appropriately investigated and resolved. This study was approved by the Ethics Committee of the Fujian Maternity and Child Health Hospital (Ethics No: 268, December 12, 2016). Written informed consent was signed by the guardians of all patients. The study was conducted in accordance with the Declaration of Helsinki (as revised in 2013).

Open Access Statement: This is an Open Access article distributed in accordance with the Creative Commons Attribution-NonCommercial-NoDerivs 4.0 International License (CC BY-NC-ND 4.0), which permits the noncommercial replication and distribution of the article with the strict proviso that no changes or edits are made and the original work is properly cited (including links to both the formal publication through the relevant DOI and the license). See: https://creativecommons.org/licenses/by-nc-nd/4.0/.

\section{References}

1. Kremer R, Aboud W, Haberfeld O, et al. Differential lung ventilation for increased oxygenation during one lung ventilation for video assisted lung surgery. J Cardiothorac Surg 2019;14:89.

2. Lu Y, Dai W, Zong Z, et al. Bronchial Blocker Versus Left Double-Lumen Endotracheal Tube for One-Lung Ventilation in Right Video-Assisted Thoracoscopic Surgery. J Cardiothorac Vasc Anesth 2018;32:297-301.

3. Mohtar S, Hui TWC, Irwin MG. Anesthetic management of thoracoscopic resection of lung lesions in small children. Paediatr Anaesth 2018;28:1035-42.

4. Umari M, Falini S, Segat M, et al. Anesthesia and fasttrack in video-assisted thoracic surgery (VATS): from evidence to practice. J Thorac Dis 2018;10:S542-54.

5. Templeton TW, Downard MG, Simpson CR, et al. Bending the rules: a novel approach to placement and retrospective experience with the 5 French Arndt endobronchial blocker in children $<2$ years. Paediatr Anaesth 2016;26:512-20.

6. Guo X, Song X, Chen X, et al. A novel technique for endobronchial blocker placement for one-lung ventilation in children under 2 years. Acta Anaesthesiol Scand 2018;62:765-72.

7. Lee JH, Bae JI, Jang YE, et al. Lung protective ventilation during pulmonary resection in children: a prospective, single-centre, randomised controlled trial. Br J Anaesth 2019;122:692-701.

8. Hammer GB, Harrison TK, Vricella LA, et al. Single lung ventilation in children using a new paediatric bronchial blocker. Paediatr Anaesth 2002;12:69-72.

9. Yun ES, Saulys A, Popic PM, et al. Single-lung ventilation in a pediatric patient using a pediatric fibreopticallydirected wire-guided endobronchial blocker. Can J 
Anaesth 2002;49:256-61.

10. Wald SH, Mahajan A, Kaplan MB, et al. Experience with the Arndt paediatric bronchial blocker. Br J Anaesth 2005;94:92-4.

11. Wigginton M, Lehrian L. Alternative methods of lung isolation in cases of pediatric bilateral thoracoscopic surgery. Paediatr Anaesth 2016;26:1209-11.

12. Cerchia E, Ferrero L, Molinaro F, et al. Pediatric Thoracoscopy and Bronchial Blockers: The Continued Search for the Ideal One-Lung Ventilation. J Laparoendosc Adv Surg Tech A 2016;26:153-6.

13. Shafy SZ, Hakim M, Kamata $M$, et al. Intracuff pressure during one-lung ventilation in infants and children. J Pediatr Surg 2019;54:1929-32.

14. Templeton TW, Templeton LB, Lawrence AE, et al. An initial experience with an Extraluminal EZ-Blocker® : A new alternative for 1-lung ventilation in pediatric patients. Paediatr Anaesth 2018;28:347-51.

15. Theroux MC, Fisher AO, Rodriguez ME, et al. Prophylactic methylprednisolone to reduce inflammation and improve outcomes from one lung ventilation in children: a randomized clinical trial. Paediatr Anaesth 2015;25:587-94.

16. Campos JH, Kernstine KH. A comparison of a left-sided Broncho-Cath with the torque control blocker univent and the wire-guided blocker. Anesth Analg 2003;96:283-9.

17. Baek SY, Kim JH, Kim G, et al. Successful one-lung ventilation by blocking the right intermediate bronchus

Cite this article as: Zhang L, Wang YP, Chen XF, Yan ZR, Zhou M. Effects of bronchial blockers on gas exchange in infants with one-lung ventilation: a single-institutional experience of 22 cases. Transl Pediatr 2020;9(6):802-808. doi: $10.21037 / \mathrm{tp}-20-391$ in a 7-year-old child: a case report. J Int Med Res 2019;47:2740-5.

18. Campos JH, Feider A. Hypoxia During One-Lung Ventilation;A Review and Update. J Cardiothorac Vasc Anesth 2018;32:2330-8.

19. Piccioni F, Templeton TW, Morris B, et al. Pediatric thoracic anesthesia: airway management for lung isolation and postoperative analgesia. Pediatr Med 2019;2:23.

20. Sutton CJ, Naguib A, Puri S, et al. One-lung ventilation in infants and small children: blood gas values. J Anesth 2012;26:670-4.

21. Ishikawa S, Lohser J. One-lung ventilation and arterial oxygenation. Curr Opin Anaesthesiol 2011;24:24-31.

22. Ishikawa $\mathrm{S}$. Alveolar recruitment maneuver as an important part of protective one-lung ventilation. J Anesth 2012;26:794-5.

23. Hammer GB, Fitzmaurice BG, Brodsky JB. Methods for single-lung ventilation in pediatric patients. Anesth Analg 1999;89:1426-9.

24. Borchardt RA, LaQuaglia MP, McDowall RH, et al. Bronchial injury during lung isolation in a pediatric patient. Anesth Analg 1998;87:324-5.

25. Hale JE, Meador MR, Mossad EB. Lung separation in children: Options and impact on gas exchange and lung compliance. Paediatr Anaesth 2019;29:915-9.

(English Language Editor: J. Teoh) 